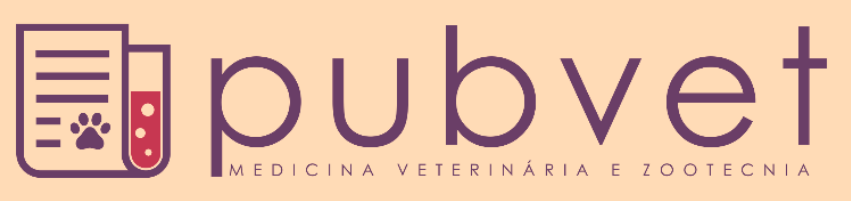

https://doi.org/10.31533/pubvet.v13n6a342.1-7

\title{
Pesquisa de Leishmania spp. em flebotomíneos (Diptera: Psychodidae) do munícipio de Iúna, Espírito Santo
}

\author{
Humberto Gripp de Faria ${ }^{1}$, Laís Regina Ferreira Magnago ${ }^{2} \bullet$, Gabriela dos Santos de Jesus ${ }^{2} \odot$, Yuri \\ Vieira Almeida ${ }^{2}$, Laisa Savergnini Poleze ${ }^{2}$, Ana Paula Madureira ${ }^{3 \bullet}$, Marcos Santos Zanini ${ }^{4 *}$ \\ ${ }^{I}$ Mestrando do Programa de Pós-Graduação em Ciências Veterinárias-PPGCV/CCAE, Universidade Federal do Espírito Santo, Alegre-ES, Brasil. \\ ${ }^{2}$ Acadêmico de Medicina Veterinária-DMVET/CCAE, Universidade Federal do Espírito Santo, Alegre-ES, Brasil. \\ ${ }^{3}$ Professora Doutora da Universidade Federal de São João del-Rei, Departamento de Engenharia de Biossistemas, São João del-Rei-MG, Brasil. \\ ${ }^{4}$ Professor Doutor da Universidade Federal do Espírito Santo, Departamento de Medicina Veterinária-DMVET/CCAE, Alegre-ES, Brasil. \\ *Autor para correspondência, E-mail: marcos.zanini@ufes.br
}

Resumo. Este estudo avaliou a fauna local de flebotomíneos vetores para Leishmaniose Tegumentar Americana (LTA) da região rural do município de Iúna, estado do Espírito Santo, Brasil. As capturas dos dípteros abrangeram cinco localidades rurais onde casos de LTA já haviam sido previamente relatados. Os critérios de escolha para a instalação das armadilhas foram propriedades com histórico anterior de casos clínicos humanos de LTA e a presença de cães sem sinais clínicos da doença, mas soropositivos para Leishmania (Viannia) braziliensis pela técnica de ELISA indireta. As coletas realizaram-se com o auxílio de armadilhas luminosas do tipo "CDC" (Centers for Diseases Controls) instaladas às $18 \mathrm{~h} 00 \mathrm{~min}$ e recolhidas às $06 \mathrm{~h} 00 \mathrm{~min}$ totalizando 336 horas de funcionamento. Entre quatorze pontos de coletas, dez apresentaram positivos para a presença de flebotomíneos sendo um total de 1148 espécimes todos processados e identificados. Uma parcela de 60 fêmeas de diferentes pontos de coleta foi submetida a técnica de reação em cadeia da polimerase (PCR) para avaliar a presença do gênero Leishmania spp. nos tubos digestivos dos dípteros sendo observada três resultados positivos para presença de ácidos nucleicos de Leishmania (Viannia) braziliensis. Entre os restantes 1088 flebotomíneos, a espécie Migonemyia migonei foi a que se apresentou mais abundante sendo responsável por 71,7\% dos espécimes, seguida por Nyssomyia intermedia 21,5\%, somando as demais espécies capturadas 6,8\%. Considerando a capacidade vetorial de $M g$. migonei e $N y$. intermedia, bem como seus hábitos antropofílicos já descritos na literatura, podemos sugerir que essas espécies possam estar atuando como transmissoras de LTA na região.

Palavras chave: Leishmania (Viannia) braziliensis, identificação, vetor, epidemiologia

\section{Search for Leishmania spp. in sandflies (Diptera: Psychodidae) from the municipality of Iúna, Espirito Santo}

\footnotetext{
Abstract. This study evaluated the local fauna of phlebotomine vectors for American Tegumentary Leishmaniasis (ATL) in the rural region of Iúna, state of Espírito Santo, Brazil. Diptera catches encompassed five rural locations where ATL cases had previously been reported. The selection criteria for the installation of the traps were properties with a previous history of human clinical cases of ATL and the presence of dogs without clinical signs of the disease, but seropositive to Leishmania (Viannia) braziliensis by the indirect ELISA technique. The collections were carried out with the aid of "CDC" type light traps (Centers for Diseases Controls) installed at 6:00 p.m. and collected at 06:00 a.m., totaling 336 operating hours. Among fourteen collection points, ten showed positive for the presence of sandflies, and a total of 1148 specimens were all processed and identified. The
} 
60 females from positive collection point was submitted to a polymerase chain reaction (PCR) technique to evaluate the presence of the genus Leishmania spp. in the digestive tubes of Diptera. Three females were positive for nucleic acids of Leishmania (Viannia) braziliensis. Among the 1148 phlebotomines, the species Migonemyia migonei was the one that presented the most abundant being responsible for $71.7 \%$ of the specimens, followed by Nyssomyia intermedia $21.5 \%$, adding the other species captured $6.8 \%$. Considering the vector capacity of $\mathrm{Mg}$. migonei and $\mathrm{Ny}$. intermedia, as well as their anthropophilic habits already described in the literature, we can suggest that these species may be acting as transmitters of ATL in the region.

Keywords: Leishmania (Viannia) braziliensis, identification, vector, epidemiology

\title{
Búsqueda de Leishmania spp. en las flebotomíneas (Diptera: Psychodidae) del munícipio de Iúna, Espírito Santo
}

\begin{abstract}
Resumen. Este estudio evaluó la fauna local de flebotomíneos vectores para Leishmaniosis Tegumentar Americana (LTA) de la región rural del municipio de Iúna, estado de Espírito Santo, Brasil. Las capturas de los dípteros abarcaron cinco localidades rurales donde los casos de LTA ya habían sido previamente reportados. Los criterios de elección para la instalación de las trampas fueron propiedades con antecedentes de casos clínicos humanos de LTA y la presencia de perros sin signos clínicos de la enfermedad, pero seropositivos para Leishmania (Viannia) braziliensis por la técnica de ELISA indirecta. Las colectas se realizaron con la ayuda de trampas luminosas del tipo "CDC" (Centros para Diseases Controls) instaladas a las $18 \mathrm{~h} 00 \mathrm{~min}$ y recogidas a las 06h00min totalizando 336 horas de funcionamiento. Entre catorce puntos de colectas, diez presentaron positivos para la presencia de flebotomíneos siendo un total de 1148 especímenes todos processados e identificados. Una porción de 60 hembras de diferentes puntos de recolección fue sometida a la técnica de reacción en cadena de la polimerasa (PCR) para evaluar la presencia del género Leishmania spp. en los tubos digestivos de los dípteros. Tres hembras fueron positivas para la presencia de ácidos nucleicos de Leishmania (Viannia) braziliensis. Entre los 1148 flebotomíneos, la especie Migonemyia migonei fue la que se presentó más abundante siendo responsable por el 71,7\% de los especímenes, seguida por Nyssomyia intermedia $21,5 \%$, sumando las demás especies capturadas el 6,8\%. Considerando la capacidad vectorial de $\mathrm{Mg}$. migonei y Ny. intermedia, así como sus hábitos antropofílicos ya descritos en la literatura, podemos sugerir que esas especies puedan estar actuando como transmisoras de LTA en la región.
\end{abstract}

Palabras clave: Leishmania (Viannia) braziliensis, identificación, vectoriales, epidemiología

\section{Introdução}

As leishmanioses são um conjunto de síndromes complexas e multifacetadas causadas por várias espécies de parasitas do gênero Leishmania (Desjeux, 2004). Consideradas as mais importantes e comuns doenças transmitidas pela picada dos flebotomíneos (Diptera, Psychodidae, Phlebotominae), podem acometer tanto os seres humanos como animais. Considerada um problema de saúde pública, atualmente é endêmica em mais de 98 países sendo estimado anualmente 0,7 a 1,0 milhão de novos casos humanos com mortalidade variando entre 20.000 a 30.000 (Lainson et al., 1979; Monteiro et al., 2005). O estado do Espírito Santo, Brasil, é considerado de transmissão endêmica para as formas cutânea e mucocutânea da Leishmaniose Tegumentar Americana (LTA), associadas à espécie Leishmania (Viannia) braziliensis (Falqueto et al., 2003; Rocha et al., 2010a). Em áreas endêmicas a taxa de infecção natural dos vetores e a identificação correta das espécies de parasitas destes dípteros são de grande importância na epidemiologia da doença (Pirajá \& Lucheis, 2014). No município de Iúna, há relatos da doença tanto em homens como animais sendo o conhecimento dos diferentes agentes envolvidos nos vários ciclos de transmissão da LTA de importância para o monitoramento do agravo. O NEMES (Núcleo de Entomologia e Malacologia do Espírito Santo) realiza desde o ano de 1997, levantamento entomológico e malacológico para obter informações sobre a fauna de vetores de importância 
epidemiológica no estado do Espírito Santo. Nestes estudos, o município de Iúna foi identificado como área endêmica de ocorrência para Lutzomyia whitmani e Lutzomyia intermedia, sendo este último identificado como a principal espécie na veiculação de L. (V.) braziliensis (Vieira et al., 2012) no Estado. Nesse contexto, esse estudo teve como objetivo avaliar a fauna local de flebotomíneos em um corte amostral no peridomicílio de moradores das regiões rurais do município de Iúna e verificar a infecção deste vetor neste município pelo gênero Leishmania.

\section{Material e métodos}

\section{Desenho do estudo}

Estudo observacional do tipo descritivo, de interesse médico e médico veterinário, com o intuito de identificar e avaliar espécies de flebotomíneos transmissores de LTA capturados no peridomicílio de moradores de cinco localidades da zona rural do município de Iúna, área endêmica com relato de vários casos em humanos e animais.

\section{Caracterização do município}

Apresentando uma população de aproximadamente 27.328 habitantes, o município de Iúna, se encontra na região sul do estado do Espírito Santo, Brasil, a uma altitude média de 661 metros, ocupando território de $460 \mathrm{Km}^{2}$, temperaturas médias variando entre 7 e $30^{\circ} \mathrm{C}$, clima tropical de altitude e Mata Atlântica como vegetação característica. Situado na Região do Caparaó, faz divisa com os municípios de Muniz Freire ao leste, Ibitirama ao sul, Irupi e Ibatiba ao norte e o Estado de Minas Gerais a oeste.

\section{Área de estudo}

O estudo foi realizado em cinco localidades pertencentes à zona rural de Iúna: São João do Príncipe, Tinguaciba, Serrinha da Torre, Santíssima Trindade e Figueira. Foram selecionados quatorze imóveis rurais sendo as coordenadas marcadas com auxílio do GPS (Global Positioning System). A instalação das armadilhas (Figura 1) realizou-se no peridomicílio das residências não mais afastadas do que 30 metros da casa sede das propriedades. A região se caracteriza por intensa modificação antrópica, nas propriedades as alterações ambientais resultaram em substituição da vegetação nativa com a instalação de diversas atividades agrárias: cafeicultura (principal atividade econômica), agricultura em geral e pecuária, sendo comum a presença peridomiciliar de vários tipos de criações de animais: bovinocultura, caprinocultura, suinocultura e avicultura; além da presença de cães (Canis familiaris), gatos (Felis catus) como animais de estimação e equinos (Equus caballus), usados como animal de trabalho em atividades de tração, transporte de carga e pessoas.

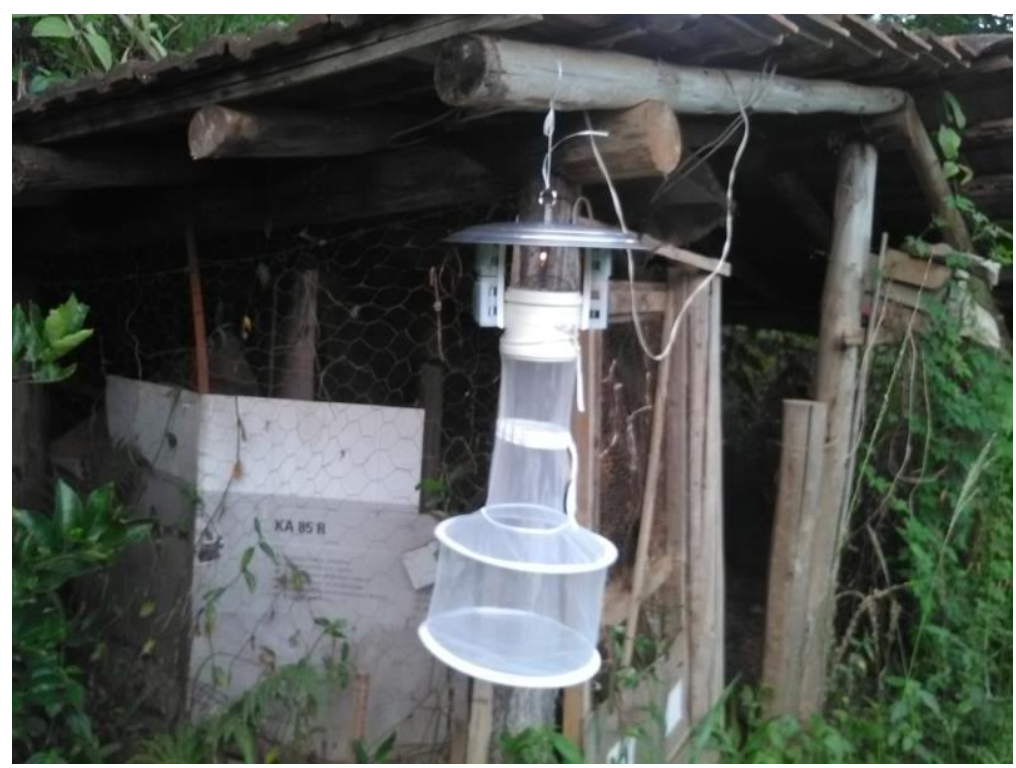

Figura 1. Armadilha luminosa do tipo CDC em funcionamento 


\section{Captura dos flebotomíneos}

As coletas ocorreram no mês de dezembro de 2015 e os trabalhos de identificação foram realizados durante 2017-2018. Utilizaram-se armadilhas luminosas do tipo CDC (Centers for Diseasis Controls) para as capturas. Foram selecionados quatorze imóveis rurais sendo as coordenadas marcadas com auxílio do GPS (Global Positioning System). Os pontos de captura (P) e suas respectivas coordenadas

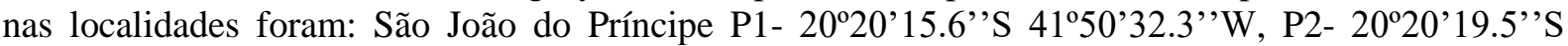
$41^{\circ} 50^{\prime} 34.2^{\prime \prime} \mathrm{W}, \mathrm{P} 3-20^{\circ} 19^{\prime} 32.8^{\prime \prime} \mathrm{S} 41^{\circ} 49^{\prime} 43.6^{\prime \prime} \mathrm{W}$; Tinguaciba P4- $20^{\circ} 15^{\prime} 50.5^{\prime}$ 'S $41^{\circ} 45^{\prime} 19.7^{\prime}$ ' $\mathrm{W}$, P5-

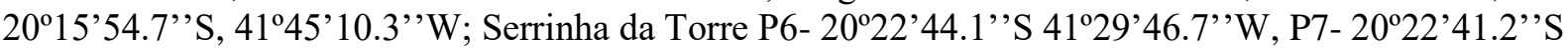

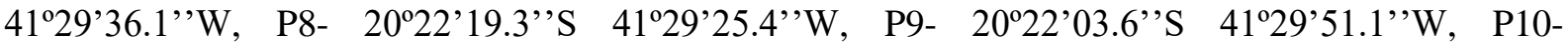

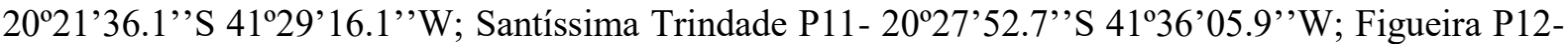

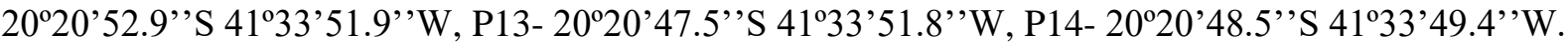
A instalação das armadilhas realizou-se no peridomicílio das residências não mais afastadas do que 30 metros da casa sede das propriedades. Respeitando os hábitos comportamentais dos flebotomíneos, as armadilhas luminosas foram montadas e ligadas às $18 \mathrm{~h} 00 \mathrm{~min}$ e recolhidas às $06 \mathrm{~h} 00 \mathrm{~min}$ do dia seguinte. Foram usadas duas armadilhas por ponto de captura totalizando 336 horas de capturas nos quatorze pontos de coleta nas cinco localidades.

\section{Processamento e identificação dos flebotomíneos}

Os flebotomíneos foram preparados de acordo com as técnicas de rotina do Laboratório de Interdisciplinar de Vigilância Entomológicas em Diptera e Hemiptera (LIVEDIH) do Instituto Oswaldo Cruz, FIOCRUZ. A identificação das espécies foi realizada segundo metodologia de Galati (2003).

\section{Avaliação da infecção natural flebotomíneos (Diptera: Psychodidae) por Leishmania spp.}

Utilizando as fêmeas foram realizadas as extrações do DNA por congelamento em nitrogênio líquido e maceração seguida de amplificação de segmentos gênicos pela técnica de Reação em Cadeia da Polimerase (PCR) para o gênero Leishmania spp. segundo Rocha et al. (2010b). As amostras positivas para o gênero Leishmania spp. tiveram o DNA submetido a nova PCR com iniciadores específicos para identificação da espécie Leishmania (V.) braziliensis (Bruijn \& Barker, 1992).

\section{Análise estatística}

Foi realizada uma estatística descritiva, sendo calculada a frequência relativa e absoluta das espécies, a razão macho e fêmea, o Índice de Dominância e o Índice de Simpson para avaliação da diversidade entre as espécies.

\section{Dados do clima}

Os dados climáticos sobre temperatura, umidade relativa do ar e índice pluviométrico, referentes ao período de estudo, foram obtidos junto ao Instituto Capixaba de Pesquisa, Assistência Técnica e Extensão Rural (INCAPER, 2015).

\section{Resultados}

Os dados climáticos registrados no mês de dezembro (Figura 2) foram de acordo com as temperaturas e umidade considerados ótimos para a ocorrência da maioria das espécies de flebotomíneos neotropicais (Lainson et al., 1979).

O somatório total das 336 horas de capturas nos 14 pontos coletados foi 1148 flebotomíneos. Excetuando a parcela de 60 fêmeas utilizadas para avaliação da presença de ácidos nucleicos de Leishmania spp., o total de flebotomíneos identificados foi 1088 (Figura 3), pertencentes a seis gêneros e nove espécies, 614 machos $(56,43 \%)$ e 474 fêmeas $(43,57 \%)$. O sucesso na captura com as armadilhas CDC foi de 0,12 flebotomíneos/hora/armadilha, pertencentes a seis gêneros e nove espécies, 614 machos $(56,43 \%)$ e 474 fêmeas $(43,57 \%)$ A razão de machos em relação às fêmeas foi de 1,29 , o Índice de Dominância foi de 0,56 e o Índice de Diversidade de Simpson foi igual a 0,44. 
Nesse estudo quatro pontos de coletas não apresentaram a presença de flebotomíneos, sendo eles: P1, P2, P5 e P9, pertencentes à localidade de São João do Príncipe, Tinguaciba e Serrinha da Torre. Os três com as maiores frequências foram P7, P8 e P13 (distritos de Serrinha da Torre e Figueira) que juntos foram responsáveis por 993 flebotomíneos. As espécies Migonemyia migonei, Nyssomyia intermedia, Nyssomyia whitmani, e Pintomyia fischer, ou seja, as que são reconhecidas como vetores de LTA representaram $96,42 \%$ do total capturado enquanto as demais espécies somaram 3,58\%.

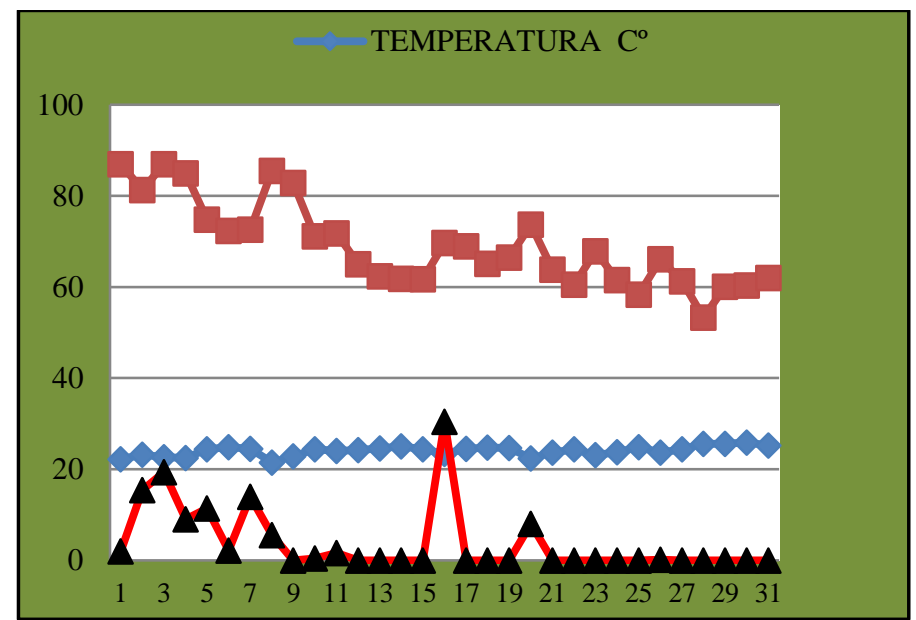

Figura 2. Dados climáticos de Iúna, ES, temperatura, umidade relativa do ar e índice pluviométrico referente ao mês de dezembro de 2015. Fonte: INCAPER, 2015.

Entre os 10 pontos de coleta com presença de flebotomíneos, após a realização da PCR aplicada as 60 fêmeas utilizando iniciadores específicos para Leishmania (V.) braziliensis (Bruijn \& Barker, 1992) verificamos três resultado positivos (3/60) representando 5\% do total, sendo dois registros no distrito de Serrinha da Torre e um resultado positivo em Figueira.

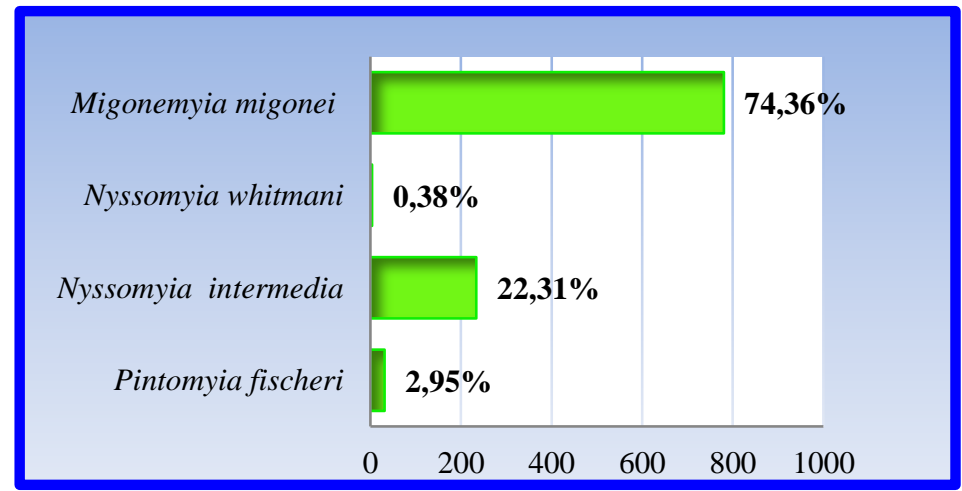

Figura 3. Espécies de flebotomíneos transmissoras de Leishmaniose Tegumentar Americana capturadas no peridomicílio de moradores de zonas rurais de Iúna/ES.

\section{Discussão}

A distribuição da LTA é influenciada por fatores geográficos e climáticos pouco conhecidos (Pirajá $\&$ Lucheis, 2014). Esses fatores determinam a distribuição de diferentes flebotomíneos vetores, parasitas e reservatórios. A complexidade da interação desses agentes nos diferentes ciclos de transmissão da doença colabora para as dificuldades em se controlar o agravo. Nas regiões mais carentes, a falta de estrutura favorece o avanço da LTA contribuindo para o aumento do número de vítimas que muitas vezes são acometidas por lesões graves e debilitantes (Desjeux, 2004).

A fauna de flebotomíneos encontrada no estado do Espírito Santo é de aproximadamente 59 espécies, cinco espécies com características antropofílicas são usualmente coletadas em áreas com ocorrência de casos de LTA: Nyssomyia intermedia, Ny. whitmani, Mg. migonei, Pi. fischeri e Pintomyia monticola, 
sendo todas incriminadas como vetores da doença, com exceção de Pi. monticola. Todos os gêneros de interesse médico capturadas nesse estudo já haviam sido relatados no estado, do total das nove espécies encontradas, quatro delas são consideradas transmissoras da L. (V.) braziliensis: Ny. intermedia, $N y$. whitmani, Mg. migonei e Pi. fischeri. Ny. intermedia é a principal espécie relacionada com a transmissão da doença no sudeste do Brasil, devido a sua alta prevalência muitos autores a consideram como a principal espécie vetor em ambientes modificados, sendo acompanhada também por $\mathrm{Mg}$. migonei e $\mathrm{Ny}$. whitmani (Meneguzzi et al., 2016).

Nesse estudo $M g$. migonei foi a espécie mais abundante, com $71,7 \%$ de frequência, influenciando diretamente o Índice de Simpson $(0,44)$. Essa prevalência nessa região sugere que em Iúna, ela possa ser um importante vetor da doença. A adaptação a ambientes modificados pela agricultura e o notável grau de antropofilia dessa espécie já foi apontado em outros relatos (Rangel \& Lainson, 2009). A espécie Mg. migonei junto com Evandromyia lenti, em estudo de fauna também na região do Caparaó, no estado de Minas Gerais, apresentaram maiores taxas de capturas em ambiente de cafezal (Saraiva et al., 2006). A espécie Pi. fischeri foi a terceira de importância vetorial no contexto das leishmanioses, representou $2,85 \%$ do total da amostra, considerada antropofílica. Esta espécie já foi relatada em grande quantidade em ambiente de cafezal no estado de Minas Gerais, em região com características ambientais parecidas com as encontradas nos locais de coleta desse estudo (Alexander et al., 2002). A espécie Nyssomyia whitmani apesar de participar do ciclo de transmissão da LTA em outros municípios do Espírito Santo, como Afonso Cláudio e ter sido a segunda espécie mais abundante em coletas na Região do Caparaó mineira (Saraiva et al., 2006), nesse estudo não se apresentou em grande número sendo somente 0,37\% dos flebotomíneos.

A diversidade de flebotomíneos em ambientes de floresta é claramente maior do que no peridomicílio, mesmo sendo dentro da mesma área de estudo, a baixa ocorrência das demais espécies de flebotomíneos em diversidade e número no peridomicílio contribui para o entendimento sobre o impacto das alterações ambientais na fauna de flebotomíneos. A modificação antrópica do meio ambiente favorece a sobrevivência de espécies com maior capacidade adaptativa, provavelmente as que possuem menores exigências alimentares e climáticas, neste contexto, justifica-se o alto percentual de 93,2\% do total de espécimes capturadas, pertencerem a somente duas espécies, $\mathrm{Ny}$. intermedia e $M g$. migonei, ambas com capacidade vetorial, e, portanto, importantes no ciclo de transmissão e na ocorrência das leishmanioses (Pita-Pereira et al., 2011).

As amostras positivas para PCR indicando a infecção por $L$. (V.) braziliensis constituem-se em um indicador da presença de flebotomíneos infectados e com capacidade de disseminar a enfermidade ao fazer o repasto sanguíneo apesar de estatisticamente não ser significativo pela pequena amostragem (3/60). Achados semelhantes quanto às espécies infectadas e também com pequeno percentual de flebotomíneos infectados para $L$. (V.) braziliensis foi relatado para o estado do Espírito Santo por Rocha et al. (2010b) quando ao examinar 1689 flebotomíneos encontrou 13 (0,77\%) espécimes infectadas entre $N y$. whitmani e $N y$. Intermedia. Estes dados permitem avaliar a presença e manutenção de forma endêmica da enfermidade.

Por fim, este conhecimento poderá melhorar as decisões nas ações de saúde para controle da leishmaniose nesta região levando em conta os vetores e o agente etiológico, permitindo medidas profiláticas que poderão ser adotadas com o intuito de diminuir a ocorrência de novos casos da doença e dos custos com os serviços de saúde.

\section{Conclusão}

Considerando a infecção por L. braziliensis em 5\% dos vetores avaliados por PCR, o Índice de Dominância 0,56 e a presença de $96,42 \%$ de espécies com capacidade vetorial no peridomicílio, é necessário que se mantenha atenção especial ao município, incluindo nesse aspecto a vigilância entomológica, uma vez que o mesmo apresenta condições favoráveis para transmissão da doença.

\section{Agradecimentos}

O presente trabalho foi realizado com apoio da Coordenação de Aperfeiçoamento de Pessoal de NívelSuperior - Brasil (CAPES) 


\section{Referências bibliográficas}

Alexander, B., Oliveria, E. B., Haigh, E. \& Almeida, L. L. (2002). Transmission of Leishmania in coffee plantations of Minas Gerais, Brazil. Memórias do Instituto Oswaldo Cruz, 97(5):627-630.

Bruijn, M. H. \& Barker, D. C. (1992). Diagnosis of New World leishmaniasis: specific detection of species of the Leishmania braziliensis complex by amplification of kinetoplast DNA. Acta Tropica, 52(1):45-58.

Desjeux, P. (2004). Leishmaniasis: current situation and new perspectives. Comparative immunology, microbiology and infectious diseases, 27(5):305-318.

Falqueto, A., Sessa, P. A., Ferreira, A. L., Vieira, V. P., Santos, C. B., Varejão, J. B. M., . . Grimaldi Jr, G. (2003). Epidemiological and clinical features of Leishmania (Viannia) braziliensis American cutaneous and mucocutaneous leishmaniasis in the State of Espirito Santo, Brazil. Memórias do Instituto Oswaldo Cruz, 98(8):1003-1010.

Galati, E. A. B. (2003). Morfologia e Taxonomia. In E. F. Rangel \& R. Lainson (Eds.), Flebotomíneos do Brasil (pp. 23-175). Rio de Janeiro, bRASIL: Editora Fiocruz.

Instituto Capixaba de Pesquisa, Assistência Técnica e Extensão Rural - INCAPER (2015). https://meteorologia.incaper.es.gov.br/

Lainson, R., Shaw, J. J., Fraiha, H., Miles, M. A. \& Draper, C. C. (1979). Chagas's disease in the Amazon Basin: I. Trypanosoma cruzi infections in silvatic mammals, triatomine bugs and man in the State of Pará, north Brazil. Transactions of the Royal Society of Tropical Medicine and Hygiene, 73(2):193-204.

Meneguzzi, V. C., Santos, C. B., Leite, G. R., Fux, B. \& Falqueto, A. (2016). Environmental niche modelling of phlebotomine sand flies and cutaneous leishmaniasis identifies Lutzomyia intermedia as the main vector species in southeastern Brazil. PloS one, 11(10): e0164580.

Monteiro, E., Silva, J. C. F., Costa, R. T., Costa, D. C., Barata, R. A., Paula, E. V., . . Dias, E. S. (2005). Leishmaniose visceral: estudo de flebotomíneos e infecção canina em Montes Claros, Minas Gerais. Revista da Sociedade Brasileira de Medicina Tropical, 38(2):147-152.

Pirajá, G. V. \& Lucheis, S. B. (2014). A vigilância epidemiológica de flebotomíneos como planejamento de ações de controle nas leishmanioses. Veterinária e Zootecnia, 21503-515.

Pita-Pereira, D., Souza, G. D., de Araújo Pereira, T., Zwetsch, A., Britto, C. \& Rangel, E. F. (2011). Lutzomyia (Pintomyia) fischeri (Diptera: Psychodidae: Phlebotominae), a probable vector of American cutaneous leishmaniasis: detection of natural infection by Leishmania (Viannia) DNA in specimens from the municipality of Porto Alegre (RS), Brazil, using multiplex PCR assay. Acta tropica, 120(3):273-275.

Rangel, E. F. \& Lainson, R. (2009). Proven and putative vectors of American cutaneous leishmaniasis in Brazil: aspects of their biology and vectorial competence. Memórias do Instituto Oswaldo Cruz, 104(7):937-954.

Rocha, L. S., Falqueto, A., Santos, C. B., Ferreira, A. L., Graça, G. C., Grimaldi Jr, G. \& Cupolillo, E. (2010a). Survey of natural infection by Leishmania in sand fly species collected in southeastern Brazil. Transactions of the Royal Society of Tropical Medicine and Hygiene, 104(7):461-466.

Rocha, L. S., Santos, C. B., Falqueto, A., Grimaldi, G. \& Cupolillo, E. (2010b). Molecular biological identification of monoxenous trypanosomatids and Leishmania from antropophilic sand flies (Diptera: Psychodidae) in Southeast Brazil. Parasitology Research, 107(2):465-468.

Saraiva, L., Lopes, J. S., Oliveira, G. B. M., Batista, F. A., Falcão, A. L. \& Andrade Filho, J. D. (2006). Estudo dos flebotomíneos (Diptera: Psychodidae) em área de leishmaniose tegumentar americana nos municípios de Alto Caparaó e Caparaó, Estado de Minas Gerais. Revista da Sociedade Brasileira de Medicina Tropical, 3956-63.

Vieira, V. P., Ferreira, A. L., Santos, C. B., Leite, G. R., Ferreira, G. E. M. \& Falqueto, A. (2012). Peridomiciliary breeding sites of Phlebotomine sand flies (Diptera: Psychodidae) in an endemic area of American cutaneous leishmaniasis in Southeastern Brazil. The American Journal of Tropical Medicine and Hygiene, 87(6):1089-1093.

Recebido: 10 de abril, 2019.

Aprovado: 20 de maio, 2019.

Publicado: 16 de junho, 2019.

Licenciamento: Este artigo é publicado na modalidade Acesso Aberto sob a licença Creative Commons Atribuição 4.0 (CC-BY 4.0), a qual permite uso irrestrito, distribuição, reprodução em qualquer meio, desde que o autor e a fonte sejam devidamente creditados. 